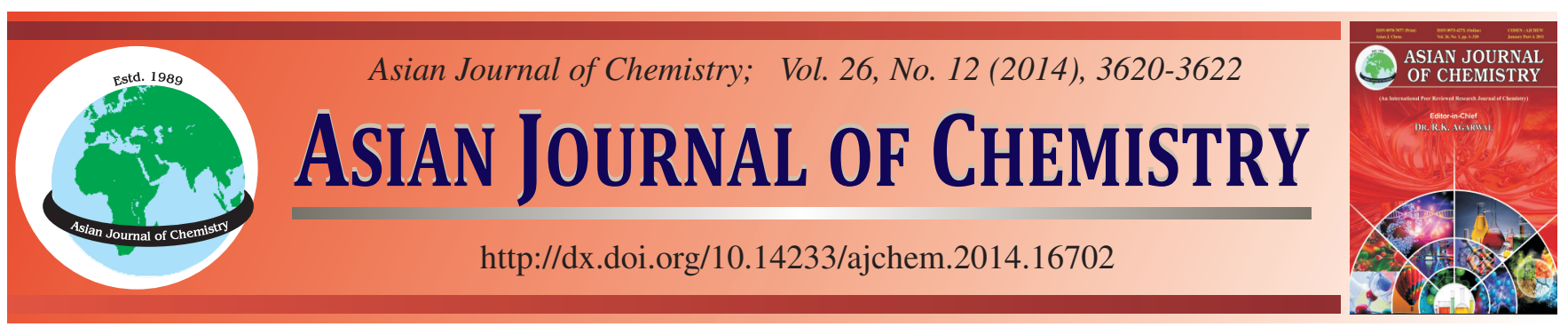

\title{
Aromatic Glycoside from Flue-Cured Tobacco (Nicotiana tabacum) Leaves and its Pyrolysis Behavior Studied by Pyrolysis-GC/MS
}

\author{
Y. YUAN ${ }^{1,2}$, R. ZHOU ${ }^{1,2, *}$, D.L. Li ${ }^{1,2}$ and G.L. FENG ${ }^{1}$
}

${ }^{1}$ Harmful Components and Tar Reduction in Cigarette Sichuan key laboratory, Chengdu 610066, P.R. China

${ }^{2}$ Technical Research Center, China Tobacco Chuanyu Industrial Co. Ltd, Chengdu 610066, P.R. China

*Corresponding author: Fax: +86 28 86005058; Tel: +86 18224499407; E-mail: yuangenyue @ foxmail.com

Received: 15 November 2013; $\quad$ Accepted: 28 January 2014;

AJC-15305

\begin{abstract}
The aromatic glycoside, named benzyl-6-O- $\alpha$-L-arabinopyranosyl(1-6)- $\beta$-D-glucopyranoside, was isolated from the leaves of Nicotiana tabacum $\mathrm{L}$. The structure of which was elucidated by analysis of its spectroscopic data. This compound's thermal behavior and pyrolysis products were also investigated by on-line pyrolysis-gas chromatography mass spectroscopy (Py-GC/MS) at $300,500,700,900{ }^{\circ} \mathrm{C}$. The results indicated that, due to the primary decomposition reaction of the O-glycosidic bound's cleavage, the characteristic and main pyrolysis product was the typical aroma constituent benzyl alcohol, suggesting that glycoside would contribute to produce specific aroma for tobacco products on heating as a novel aroma precursor.
\end{abstract}

Keywords: Nicotiana tabacum, Benzyl-6-O- $\alpha$-L-arabinopyranosyl(1-6)- $\beta$-D-glucopyranoside, Pyrolysis, Py-GC/MS.

\section{INTRODUCTION}

Nicotiana tabacum $\mathrm{L}$. is the most commonly grown of all plants in the Nicotiana genus of the family Solanaceae, whose leaves can be used as an insecticide and medicinally for anaesthetic ${ }^{1}$, but especially for cigarettes and other tobacco products $^{2}$. The flue-cured tobacco (Nicotiana tabacum L.) var. honghuadajinyuan is one of the main tobacco cultivar in China, most planted in high altitude areas of Sichuan and Yunnan province, selected and improved from Virginia flue-cured tobacco about fifty years ago. It has draw much attention for its superior quality, strong resistance, low fertilizer requirement and eurytopicity ${ }^{3-5}$.

There has been consideration that the glycosidic components of tobacco leaves may contribute to generating aroma and taste in the curing and aging processes of flue-cured tobacco ${ }^{6}$ and several kind of glycosides were isolated from the leaves of flue-cured tobacco (Nicotiana tabacum L. ${ }^{6-9}$. However, most of these reports were concentrated on the natural extraction, structure identification, synthesis and biological activities and the thermal behavior of theses glycosides were seldom studied. In the course of investigation on the potential aroma precursors of $N$. tobacum L. var. honghuadajinyuan, a known aromatic glycoside ${ }^{10-18}$, named benzyl-6-O- $\alpha$-L-arabinopyranosyl(1-6)- $\beta$-D-glucopyranoside (BAG) was separated, whose presence is reported in Nicotiana species for the first time.
To further explore the possibility of benzyl-6-O- $\alpha-\mathrm{L}-$ arabinopyranosyl(1-6)- $\beta$-D-glucopyranoside (BAG) as aroma precursor, on-line pyrolysis-gas chromatography mass spectroscopy (Py-GC/MS) was used to study its decomposition process and pyrolysis products.

\section{EXPERIMENTAL}

The leaves of the flue-cured tobacco (Nicotiana tabacum L.) var. honghuadajinyuan are collected in Xichang region, Sichuan Province, China, in September 2010 and were identified by Prof. Y.L. Peng, Chengdu Institute of Biology, Chinese Academy of Sciences. A voucher specimen (zr2011081001) was deposited at the Herbarium of Chengdu Institute of Biology, CAS. All solvents including petroleum ether (60$90{ }^{\circ} \mathrm{C}$ ) were distilled prior to use.

NMR data were obtained on a Bruker Avance 600 spectrometer. ESI-MS and HR-ESI-MS were performed on a BioTOFQ mass spectrometer. Silica gel (200-300 mesh) for column chromatography and silica gel GF254 (10-40 mm) for thin layer chromatography (TLC) were purchased from Qingdao Haiyang Chemical Company, China. Semi-preparative HPLC was performed on a Waters 2605 LC system with a Waters RP-18 column $\left(20 \times 250 \mathrm{~mm}^{2}, 3 \mathrm{~mL} \mathrm{~min}^{-1}\right)$.

Extraction and isolation procedure: The air-dried powder of the leaves of $N$. tobacum L. cultivar honghuadajinyuan $(5 \mathrm{~kg})$ were extracted with $95 \%$ ethanol (45 L) for three times 
at $65^{\circ} \mathrm{C}$ and condensed. The concrete was suspended in $\mathrm{H}_{2} \mathrm{O}$ $(12.5 \mathrm{~L})$ at $65^{\circ} \mathrm{C}$. The aqueous phase was obtained by removing the insoluble constitution and partitioned successively with petroleum ether, ethyl acetate and $n$-butanol. Only the $n$ butanol extract was applied, considering it contains most of the glycosidic components with strong polarity and relatively higher hydrophilicity. The aqueous phase obtained after repeatedly dispersion and filtration of the $n$-butanol extract (750 g) in $\mathrm{H}_{2} \mathrm{O}(6.5 \mathrm{~L})$ at $65^{\circ} \mathrm{C}$ was subjected to macroporous resin D101 column, sequentially eluted with water, $20 \%$ ethanol, $40 \%$ ethanol, $60 \%$ ethanol, $80 \%$ ethanol and ethanol. According to the results of silica gel column chromatography, no glycosides existed in the eluates of $60 \%$ ethanol, $80 \%$ ethanol and ethanol. The eluates of $20 \%$ ethanol and $40 \%$ ethanol with similar TLC profile were combined and then crystallized for several times to yield Fraction A (1050 g). Upon further silica gel column chromatography $\left(\mathrm{CHCl}_{3} / \mathrm{MeOH}\right.$ $15: 1$ to $0: 1)$, fractions were collected and combined based on TLC, giving nine subfractions $\mathrm{AA}, \mathrm{AB}, \mathrm{AC}, \mathrm{AD}, \mathrm{AE}, \mathrm{AF}, \mathrm{AG}$, $\mathrm{AH}, \mathrm{AI}$. After repeated purification of AI (140 g) by molecular sieve, the compound BAG $(0.02 \mathrm{~g})$ was obtained by separation of this part with preparative HPLC $\left(25 \% \mathrm{MeOH}-\mathrm{H}_{2} \mathrm{O}\right)$ at the flow rate of $3 \mathrm{~mL} \mathrm{~min}^{-1}$.

Benzyl-6-O- $\alpha$-L-arabinopyranosyl(1-6)- $\beta$-D-glucopyranoside (BAG), white powder, ${ }^{1} \mathrm{H} N \mathrm{NM}\left(\mathrm{C}_{5} \mathrm{D}_{5} \mathrm{~N}, 600 \mathrm{MHz}\right)$ : 反 $3.26\left(1 \mathrm{H}, \mathrm{m}, \mathrm{H}^{\prime}-2\right)$, 3.37-3.38 (2H, m), 3.44-3.61 (4H, m), $3.75\left(1 \mathrm{H}, \mathrm{dd}, J=11.4,5.8 \mathrm{~Hz}, \mathrm{H}^{\prime}-6\right), 3.85(2 \mathrm{H}), 4.11(1 \mathrm{H}, \mathrm{dd}$, $\left.J=11.5,2.0 \mathrm{~Hz}, \mathrm{H}^{\prime}-6\right), 4.33\left(1 \mathrm{H}, \mathrm{d}, J=6.8 \mathrm{~Hz}, \mathrm{H}^{\prime \prime}-1\right), 4.36$ $\left(1 \mathrm{H}, \mathrm{d}, J=7.9 \mathrm{~Hz}, \mathrm{H}^{\prime}-1\right), 4.65(1 \mathrm{H}, \mathrm{d}, J=11.8 \mathrm{~Hz}, \mathrm{H}-7), 4.90$ $(1 \mathrm{H}, \mathrm{d}, J=11.8 \mathrm{~Hz}, \mathrm{H}-7), 7.25-7.41(5 \mathrm{H}, \mathrm{m}, \mathrm{H}-2-6) ;{ }^{13} \mathrm{C} \mathrm{NMR}$ $\left(\mathrm{C}_{5} \mathrm{D}_{5} \mathrm{~N}, 150 \mathrm{MHz}\right)$, aglycone moiety: $\delta 139.2(\mathrm{C}-1), 129.4$ (C-2), 129.3 (C-3), 128.8 (C-4), 129.3 (C-5), 129.4 (C-6), 72.5 (C-7); sugar moiety: $\delta 103.5$ (C-1'), 75.2 (C-2'), 78.1 (C-3'), 70.8 (C-4'), 77.1 (C-5'), 69.6 (C-6'), 105.3 (C-1"), 72.0 (C2"), 74.3 (C-3"), 69.7 (C-4"), 66.8 (C-5").

Pyrolysis-GC/MS procedure: The online Py-GC/MS analysis was carried out with an American CDS5200 Pyroprobe coupled directly to a PerkinElmer Clarus 600 GCMA. Pyrolysis temperature was set up at $300,500,700$ and $900{ }^{\circ} \mathrm{C}$, respectively, heating from $50{ }^{\circ} \mathrm{C}$ at the rate of $10{ }^{\circ} \mathrm{C} \mathrm{min}{ }^{-1}$ for $15 \mathrm{~s}$. GC qualitative analysis was conducted with a DB-5 fused silica capillary column $(30 \mathrm{~m} \times 0.25 \mathrm{~mm}$ i.d., film thickness $0.25 \mu \mathrm{m}$ ); flow rate of He was $1 \mathrm{~mL} \mathrm{~min}^{-1}$; column temperature was held at $50{ }^{\circ} \mathrm{C}$ for $1 \mathrm{~min}$, then raised to $260^{\circ} \mathrm{C}$ at the rate of $5{ }^{\circ} \mathrm{C} \mathrm{min}{ }^{-1}$; split ratio $50: 1$; injector temperature $250{ }^{\circ} \mathrm{C}$; ion source temperature $230{ }^{\circ} \mathrm{C}$; inlet line temperature $250{ }^{\circ} \mathrm{C}$; EIMS scan range 50-450 amu; EI ionization energy $70 \mathrm{eV}$; solvent delay $2 \mathrm{~min}$. The pyrolysis products were identified on the basis of their high resolution mass spectra.

\section{RESULTS AND DISCUSSION}

Identification of benzyl-6-O- $\alpha$-L-arabinopyranosyl(16)- $\boldsymbol{\beta}$-D-glucopyranoside: The compound BAG (Fig. 1), a white powder, revealed a m.f. $\mathrm{C}_{18} \mathrm{H}_{26} \mathrm{O}_{10}$, based on the molecular ion at $m / z 425.1413\left([\mathrm{M}+\mathrm{Na}]^{+}\right.$, calc. 425.3878$)$ in the HR-ESI$\mathrm{MS}$ and the 18 carbon signals showed by the ${ }^{13} \mathrm{C}$ NMR spectrum, indicating six degrees of unsaturation. Its optical rotation was $[\alpha]_{\mathrm{D}}{ }^{25}-39.7^{\circ}\left(\mathrm{c} 0.10, \mathrm{H}_{2} \mathrm{O}\right)$. The ${ }^{1} \mathrm{H}$ NMR signals at $\delta_{\mathrm{H}} 7.41(2 \mathrm{H}$, $\mathrm{d}, J=7.2 \mathrm{~Hz}, \mathrm{H}-3,5), 7.32(2 \mathrm{H}, \mathrm{t}, J=7.2 \mathrm{~Hz}, \mathrm{H}-2,6)$ and 7.25 $(1 \mathrm{H}, \mathrm{t}, J=7.2 \mathrm{~Hz}, \mathrm{H}-4)$ suggested a monosubstituted benzene ring, following a chiral methylene before oxygen at $\delta_{\mathrm{H}} 4.65$ $(1 \mathrm{H}, \mathrm{d}, J=11.8 \mathrm{~Hz}, \mathrm{H}-7)$ and $4.90(1 \mathrm{H}, \mathrm{t}, J=11.8 \mathrm{~Hz}, \mathrm{H}-7)$. The ${ }^{13} \mathrm{C}$ NMR spectrum disclosed the presence of two sugar group $\left(\delta_{\mathrm{C}} 103.5\right.$ and 105.3$)$ and glucosyl group $\left(\delta_{\mathrm{C}} 75.2,78.1\right.$, $70.8,77.1$ and 69.6). To further confirm the structure of dualglycoside, the acid hydrolysis reaction was conducted by adding BAG $(5 \mathrm{mg})$ into $2 \mathrm{~N} \mathrm{HCl}(2 \mathrm{~mL})$ solution and reflux heating for $0.5 \mathrm{~h}$. The aqueous solution left after ethyl acetate extraction of the reation mixture, was analysed by TLC, and the results proved the existence of both D-glucose and L-arabinose in BAG's hydrolyzate. Above all the information mentioned, compound BAG was characterized as benzyl alcohol bioside, more precisely as benzyl-6-O- $\alpha$-L-arabinopyranosyl(1-6)- $\beta$ D-glucopyranoside by comparison with previously published data $^{17}$

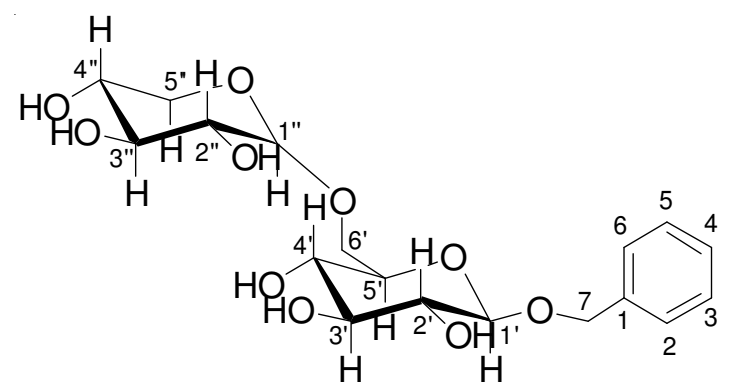

Fig. 1. Structure of benzyl-6-O- $\alpha$-L-arabinopyranosyl(1-6)- $\beta$-Dglucopyranoside

Pyrolysis-GC/MS analysis of BAG: The temperature chosen to carry out the on-line pyrolysis-gas chromatography mass spectroscopy (Py-GC/MS) were 300, 500, 700 and $900{ }^{\circ} \mathrm{C}$. The pyrolysis data, including retention time $\left(t_{R}\right)$, molecular weight (MW), assigned formula and relative peak area proportions for each identified pyroproducts of compound BAG are listed in Table-1.

According to the results, no compounds could be detected at $300{ }^{\circ} \mathrm{C}$, suggesting BAG's certain feature of heat-resistance. At 500, 700 and $900{ }^{\circ} \mathrm{C}$, benzyl alcohol was obviously the most favorable product, with the relative intensity of 66.45 , 75.65 and $62.07 \%$, respectively. Along with benzyl alcohol, there were also 3,4-altrosan, D-glucuronic acid and D-allose, with the relative intensity lower than $10 \%$, which derived from the disaccharide part of BAG. These pyroproducts proved that the rupture of the O-glycosidic bound was the primary decomposition reaction during the pyrolysis procedure of BAG and the $\alpha$-glycosidic bound between benzylidene and L-arabinose was more likely to cleave than the $\beta$ 1-6 glycosidic bound between L-arabinose and D-glucose, generating more benzyl alcohol.

Compared with the pyroproducts at lower temperatures $\left(500\right.$ and $\left.700{ }^{\circ} \mathrm{C}\right)$, benzene, toluene, ethylbenzene and benzaldehyde could be observed at $900{ }^{\circ} \mathrm{C}$, which were the byproducts of benzylalcohol following futher degradation.

The Py-GC/MS results indicated that, BAG had the highest pyrolysis efficiency at $700{ }^{\circ} \mathrm{C}$, producing the largest amount of benzyl alcohol and it could be considered as a novel aroma precursor in tobacco products, because during high temperature 


\begin{tabular}{|c|c|c|c|c|c|c|c|}
\hline \multicolumn{8}{|c|}{$\begin{array}{l}\text { TABLE-1 } \\
\text { PYROLYSIS-GC/MS RESULTS OF BAG AT DIFFERENT TEMPERATURES }\end{array}$} \\
\hline \multirow{2}{*}{$t_{R}(\min )$} & \multirow{2}{*}{ Compounds of pyrolysis } & \multirow{2}{*}{ m.f. } & & \multicolumn{4}{|c|}{ Area $(\%)$} \\
\hline & & & MW & $300^{\circ} \mathrm{C}$ & $500^{\circ} \mathrm{C}$ & $700^{\circ} \mathrm{C}$ & $900^{\circ} \mathrm{C}$ \\
\hline 2.53 & Benzene & $\mathrm{C}_{6} \mathrm{H}_{6}$ & 78 & nd & nd & nd & 3.66 \\
\hline 3.68 & Toluene & $\mathrm{C}_{7} \mathrm{H}_{8}$ & 92 & nd & nd & nd & 4.41 \\
\hline 5.39 & Ethyl benzene & $\mathrm{C}_{8} \mathrm{H}_{10}$ & 106 & nd & nd & nd & 2.98 \\
\hline 9.66 & Benzaldehyde & $\mathrm{C}_{7} \mathrm{H}_{6} \mathrm{O}$ & 106 & nd & nd & nd & 2.59 \\
\hline 11.62 & Benzyl alcohol & $\mathrm{C}_{7} \mathrm{H}_{8} \mathrm{O}$ & 108 & nd & 66.45 & 75.65 & 62.07 \\
\hline 14.52 & 3,4-Altrosan & $\mathrm{C}_{6} \mathrm{H}_{10} \mathrm{O}_{5}$ & 162 & nd & 7.67 & 5.40 & 6.20 \\
\hline 17.19 & D-Glucuronic acid & $\mathrm{C}_{6} \mathrm{H}_{10} \mathrm{O}_{7}$ & 196 & nd & 15.92 & 9.34 & 11.80 \\
\hline 26.19 & D-Allose & $\mathrm{C}_{6} \mathrm{H}_{12} \mathrm{O}_{6}$ & 180 & nd & 9.95 & 9.62 & 6.30 \\
\hline
\end{tabular}

treatment, it would release a significant amount of benzyl alcohol, which was one of the most dominant aroma constituents in many ways.

\section{Conclusion}

In continuation of our project to search for possible aroma precursors in flue-cured tobacco (Nicotiana tabacum L.) var. honghuadajinyuan, hereby we have isolated and identified the benzyl-6-O- $\alpha$-L-arabinopyranosyl(1-6)- $\beta$-D-glucopyranoside from Nicotiana tabacum L. The pyrolysis-GC/MS analysis showed the compound could regenerate typical aroma components on heating, suggesting its further application to be used as additive aroma precursor of tobacco products.

\section{ACKNOWLEDGEMENTS}

This work was supported by grants from the key project of the Science and Technology Department of Sichuan Provice (P.R. China) entitled with 'the Research of Glycosides as Aroma Precursors in Flue-cured Tobacco (Nicotiana tabacum L.) var. honghuadajinyuan from Different Areas' (Grant No. 2011JYZ036).

\section{REFERENCES}

1. S. Knapp, M.W. Chase and J.J. Clarkson, Taxon, 53, 73 (2004)

2. Z.Y. Zhang, A.M. Lu and G.D. William, Flora of China, Science Press, Beijng, vol. 17, pp. 300-332 (1994).
3. H. Cheng, F.S. Sun, S.L. Zhai, X.H. Xu, C.Y. Wang, S.F. Wang, A.H. Wang and H.Y. Wang, Chin. Tobacco Sci., 30, 5 (2009).

4. W. Zheng, R.F. Xu, C. Wang, A.C. Xu, W.Y. Hu and G.B. Deng, Chin. Tobacco Sci., 32, 22 (2011).

5. H. Cheng, F. Sun, S.L. Zhai, X.H. Xu, C.Y. Wang, S.F. Wang, A.H. Wang and H. Wang, Chin. Tobacco Sci., 33, 71 (2012).

6. H. Tazaki, H. Kodama, A. Ohnishi and T. Fujimori, Agric. Biol. Chem., 55, 1889 (1991).

7. H. Kodama, T. Fujimori and K. Kato, Agric. Biol. Chem., 49, 2537 (1985).

8. H. Tazaki, H. Kodama, T. Fujimori and A. Ohnishi, Agric. Biol. Chem., 50, 2231 (1986).

9. G.Y.Y. Yang, W. Zhao, Y.K. Chen, Z.Y. Chen, Q.F. Hu and M.M. Miao, Asian J. Chem., 25, 4932 (2013).

10. S.Y. Lee, K.H. Kim, I.K. Lee, K.H. Lee, S.U. Choi and K.R. Lee, Arch. Pharm. Res., 35, 415 (2012).

11. T. Kikuchi, J. Zhang, Y. Huang, K. Watanabe, K. Ishii, A. Yamamoto, M. Fukatsu, R. Tanaka and T. Akihisa, Chem. Biodivers., 9, 1221 (2012).

12. S. Nakamura, Y. Zhang, H. Matsuda, K. Ninomiya, O. Muraoka and M. Yoshikawa, Chem. Pharm. Bull. (Tokyo), 59, 1020 (2011).

13. Z. Ali, F. Fronczek and I. Khan, Planta Med., 74, 178 (2008).

14. S. Nakamura, X. Li, H. Matsuda, K. Ninomiya, T. Morikawa, K. Yamaguti and M. Yoshikawa, Chem. Pharm. Bull. (Tokyo), 55, 1505 (2007).

15. A. Itoh, N. Oya, E. Kawaguchi, S. Nishio, Y. Tanaka, E. Kawachi, T. Akita, T. Nishi and T. Tanahashi, J. Nat. Prod., 68, 1434 (2005).

16. D. Chassagne, J. Crouzet, C.L. Bayonove, J.M. Brillouet and R.L. Baumes, Phytochemistry, 41, 1497 (1996).

17. S. De Rosa, A. De Giulio and G. Tommonaro, Phytochemistry, 42, 1031 (1996).

18. B. Cui, M. Nakamura, J. Kinjo and T. Nohara, Chem. Pharm. Bull. (Tokyo), 41, 178 (1993). 